\title{
Peranan Meaning of Work Memediasi Hubungan antara Dukungan Organisasi dan Kreativitas Karyawan
}

\author{
Jovian Jonathan Lieando dan Yanuar \\ Program Studi Manajemen Fakultas Ekonomi \& Bisnis \\ Universitas Tarumanagara \\ Email: joelieando@yahoo.com
}

\begin{abstract}
This study investigates the effects of perceived organizational support (POS) on meaning of work and employee creativity on PT. CIPTAHUTAMA JAYA. Data was collected through a survey of 100 employees, and structural equational model (SEM) was used to test the research hypotheses. The results indicate that POS have positive effects on the meaning of work and employee creativity. While the mediating effect of meaning of work on the relationship between POS and employee creativity is only partially supported.
\end{abstract}

Keywords: Employe Creativity, Perceived Organiational Support, Meaning of Work

\begin{abstract}
Abstrak: Penelitian ini menginvestigasi efek dari dukungan organisasi terhadap makna kerja dan kreativitas karyawan pada PT. CIPTAHUTAMAJAYA. Data yang telah terkumpul berasal dari survey terhadap 100 karyawan perusahaan. Structural Equation Model digunakan untuk menguji hipotesis dari penelitian ini. hasilnya menunjukan bahwa dukungan organisasi memiliki efek positif terhadap makna kerja dan kreativitas karyawan. Sementara itu efek mediasi dari makna kerja terhadap hubungan antara dukungan organisasi dan kreativitas karyawan hanya didukung sebagian
\end{abstract}

Kata kunci: Kreativitas Karyawan, Dukungan Organisasi, Makna Kerja

\section{LATAR BELAKANG}

Dalam suatu perusahaan diperlukan sumber daya manusia yang handal untuk menghasilkan kinerja yang maksimal dan memajukan perusahaan itu sendiri. Fungsi manajemen sumber daya manusia menurut Mondy dan Martocchio (2016; dalam Mondy \& Martocchio, 2016: h. 25). Terkait dengan defenisi tersebut, Manajemen Sumber Daya Manusia adalah pemanfaatan karyawan untuk mencapai tujuan organisasi. Fungsi dari Manajemen Sumber Daya Manusia sendiri terbagi menjadi 6 meliputi : staffing, performance management, human resource development, compensation, employee and labor relations, safety and health.

Oleh karena itu jaman sekarang dimana perusahaan saling bersaing untuk menjadi yang terbaik diperlukanya kreativitas yang baik terutama bagi karyawan agar dapat meningkatkan kinerja dan mutu perusahaan dengan begitu perusahaan dapat berkembang dan bersaing dengan kompetitor lainnya.

Sekalipun banyak faktor yang mempengaruhi kreativitas karyawan namun dijelaskan dalam Yu and Frenkel's (2013) menemukan bahwa dukungan organisasi (POS) tidak memberikan pengaruh langsung dengan kreativitas karyawan. Begitu juga dengan studi Li Zhang, Qiong Bu, and Sooyeon Wee (2016). Oleh karena itu diperlukan variabel perantara untuk menghubungkan dukungan organisasi dengan kreativitas karyawan. Mengenai research gap tersebut, studi ini mengadopsi penelitian Yilmaz Akgunduz, Ceylan Alkan, Ozge Adan Goek (2018), Yilmaz Akgunduz, Gaye Kizilcalioglu, Sabahat Ceylin Sanli (2013), dan 
Cohen-Meitar, R., Carmeli, A., \& Waldman, D. A. (2009) yang menjelaskan bahwa makna kerja memiliki pengaruh terhadap kreativitas karyawan.

\section{KAJIAN TEORI}

Perceived Organizational Support. Teori yang digunakan adalah Social Exchange Theory (SET), yang di kemukakan oleh Blau (1964), Teori ini menjelaskan tentang perubahan sosial yang terjadi di lingkungan kerja dan juga perilaku manusia. Teori ini juga menjelaskan kontribusi yang di berikan karyawan terhadap organisasi dan harapan-harapan yang dimiliki karyawan sebagai hasil dari interaksi yang mereka lakukan selama bekerja. Menurut SET, saat seseorang memberikan bantuan kepada orang lain, orang itu akan mengharapkan bantuan yang dia berikan akan di balas di kemudian hari.

Organizational Support (dukungan organisasi) menurut Eisenberger et al (1986; dalam Wong \& Wong., 2017: h. 5) merupakan tindakan organisasi untuk menghargai kontribusi yang diberikan karyawan dalam organisasi

Meaning of Work. Meaning Of Work (Makna kerja) menurut Gaggioti, (2006:4) adalah sekumpulan nilai-nilai, keyakinan-keyakinan, sikap dan harapan yang orang-orang miliki dalam hubungannya dengan kerja

Sedangkan menurut Koeswara (1992:62) Makna kerja bukan dirasakan dari pekerjaan itu sendiri, tetapi bagaimana individu mampu menunjukkan keberaniannya dalam berekspresi, keunikannya dan keistimewaannyaa dalam bekerja sehingga ia dapat merasakan makna dan komitmen pribadi terhadap pekerjaan yang di lakukan dan menjadi lebih bertanggung jawab terhadap kehidupannya.

Menurut Harpaz and Fu (2002) makna kerja adalah kepercayaan signifikan dimana seorang individu percaya bahwa bekerja adalah sebuah elemen utama dalam kehidupan manusia yang terjadi pada sebagian besar hidup mereka.

Employee Creativity. Employee Creativity (kreativitas karyawan) menurut Scott \& Bruce, 2016 adalah suatu kemampuan untuk menciptakan dan menggunakan ide-ide baru yang berguna bagi perusahaan.

Menurut Shin, Kim, Lee, and Bian, 2012 Kreativitas karyawan didefinisikan sebagai cara untuk dapat memproduksi ide-ide baru dan berguna tentang produk, jasa, proses, dan prosedur oleh seorang karyawan.

Sedangkan menurut Gong, Huang, and Farh, (2009), Shalley, Zhou and Oldham, (2004) kreativitas karyawan berarti penggunaan dan pengembangan ide-ide kreatif yang memungkinkan organisasi untuk dapat menyesuaikan diri dengan perubahan pasar dan mampu merespon peluang untuk memenangkan persaingan bisnis.

Kaitan antara Dukungan Organisasi dan Makna Kerja. Menurut penelitian SET (Social Exchange Theory) yang di kemukakan oleh Blau, (1964) jika karyawan melihat bahwa mereka mendapat dukungan dari organisasi maka mereka akan memberikan kontribusi yang lebih besar kepada perusahaan sebagai balasan dari dukungan yang mereka terima dari organisasi. Karyawan dipengaruhi oleh pengetahuan, dukungan, sumber daya, dan peluang seperti kekuatan formal dan informal yang di berikan oleh organisasi. Karyawan yang dipengaruhi oleh meaning of work atau makna kerja juga menunjukan ciri-ciri peningkatan insting dalam bekerja dan lebih bermotivasi. Hasil penelitian ini juga sejalan dengan penelitian yang dilakukan oleh Wang, Z., \& Xu, H. (2019), Yilmaz Akgunduz (2017), dan Regina Martha Tanudjaja, (2013) 
Kaitan antara Makna Kerja dan Kreativitas Karyawan. Menurut Liu (2016) karyawan dapat bekerja lebih effisien dan kreatif jika mereka merasakan suasana hati yang baik sehingga produktivitas akan semakin meningkat. Dalam Kimet al., (2009). Dari pendapat ini diketahui bahwa makna kerja yang baik dapat meningkatkan kreativitas karyawan. Jika sebuah organisasi dapat menciptakan makna pekerjaan yang baik mereka tidak hanya dapat mengurangi jumlah perpindahan karyawan tetapi mereka juga dapat meningkatkan kepuasan karyawan dan kreativitas.

Penelitian ini juga didukung oleh penetlian yang sudah ada sebelumnya seperti Yilmaz Akgunduz, Ceylan Alkan, Oezge Adan Goek (2017), Yilmaz Akgunduz, Gaye Kizilcalioglu, Sabahat Ceylin Sanli (2016), dan Cohen-Meitar, R., Carmeli, A., \& Waldman, D. A. (2009)

Kaitan antara Dukungan Organisasi dan Kreativitas Karyawan dengan Makna kerja sebagai Mediasi. Hasil ini didukung oleh penelitian Yilmaz Akgunduz, Ceylan Alkan, Oezge Adan Goek (2017) Hasil dari studi ini menunjukan bahwa kreativitas karyawan akan meningkat saat karyawan dapat memahami makna kerja yang dirasakan melalui dukungan organisasi dengan begitu karyawan dapat berkontribusi terhadap perusahaan.

\section{Kerangka Pemikiran}

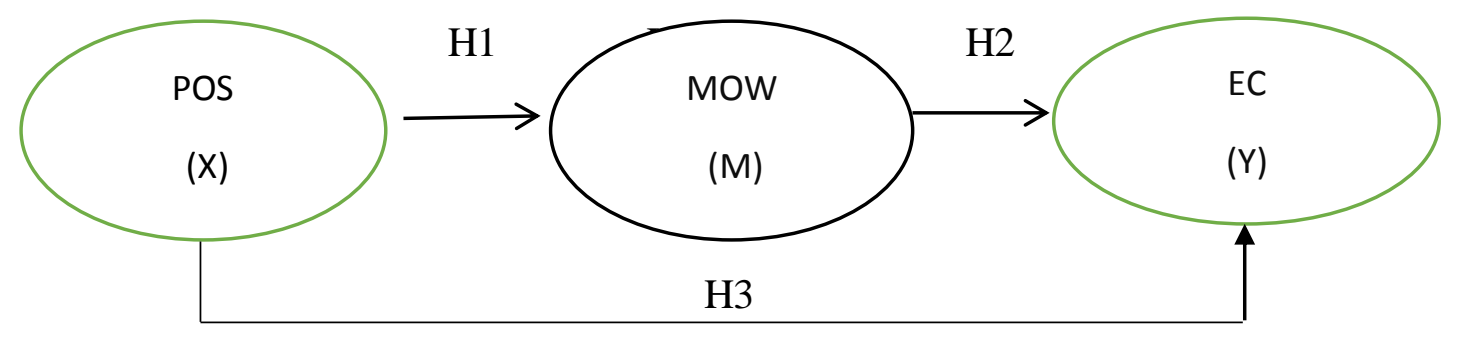

\section{Hipotesis}

$\mathrm{H}_{1}$ : Perceived Organizational Support memiliki pengaruh positif Meaning of Work

$\mathrm{H}_{2}$ : Meaning of work memiliki pengaruh positif terhadap Employee Creativity

$\mathrm{H}_{3}$ : Organizational Support memiliki pengaruh positif terhadap Employee Creativity dengan Meaning of Work sebagai mediasi.

\section{METODOLOGI}

Subjek dan populasi dari penelitian ini adalah karyawan PT. CIPTAHUTAMAJAYA yang berdomisili di Ambon. Teknik pengumpulan sample yang peneliti gunakan adalah nonprobability sampling dengan metode purpose sampling dengan ukuran sebanyak 100 orang. Penelitian ini menggunakan teknik analisis PLS-SEM yang terdiri dari dua analisis yaitu outer model dan inner model.

Operasionalisasi Variabel Perceived Organizational Support. Perceive Organizational Support sebagai variabel independen memiliki 5 indikator yang digunakan untuk menilai variabel dengan menggunakan skala likert, indikator tersebut terdiri dari, masukan dari atasan, kepedulian pribadi dari atasan, bimbingan dari atasan, dan dukungan karir dari perusahaan. Kelima indikator tersebut peneliti adaptasi dari penelitian terdahulu (Y. Akgunduz et al. 2018) 
Operasionalisasi Variabel Meaning of Work. Meaning of Work sebagai variabel mediasi indikator yang digunakan untuk menilai variabel dengan menggunakan skala likert, indikator tersebut terdiri dari, pentingnya pekerjaan bagi diri, makna pribadi dari pekerjaan, arti pekerjaan bagi diri, pengalaman yang di dapatkan dari pekerjaan, dan perasaan terhadap peluang yang di dapatkan kelima indikator tersebut peneliti adaptasi dari penelitian terdahulu (Y.Akgunduz et al. 2018 dan Lips-Wiersma, M., \& Wright, S. 2012).

Operasionalisasi Variabel Employee Creativity. Employee Creativity sebagai variabel dependen memiliki 5 indikator yang digunakan untuk menilai variabel dengan menggunakan skala likert, indikator tersebut terdiri dari, identifikasi peluang dan cara baru dalam bekerja, ide baru dalam memecahkan masalah, ide baru tetapi masih berhubungan dengan pekerjaan, originalitas dalam pekerjaan, dan mampu berpikir kreatif. kelima indikator tersebut peneliti adaptasi dari penelitian terdahulu (Y. Akgunduz et al. 2018)

\section{HASIL UJI STATISTIK}

Uji Outer Model. Uji model terdiri dari Uji Validitas dan Uji Reliabilitas.

Tabel 1. Tabel Cross Loadings

\begin{tabular}{|c|c|c|c|}
\hline $\begin{array}{c}\text { Kode } \\
\text { indkator }\end{array}$ & $\begin{array}{c}\text { Organizational } \\
\text { Support }\end{array}$ & $\begin{array}{c}\text { Meaning } \\
\text { of Wrok }\end{array}$ & $\begin{array}{c}\text { Employee } \\
\text { Creativity }\end{array}$ \\
\hline POS1 & $\mathbf{0 , 7 9 6}$ & 0,436 & 0,617 \\
\hline POS2 & $\mathbf{0 , 8 7 5}$ & 0,496 & 0,688 \\
\hline POS3 & $\mathbf{0 , 9 1 2}$ & 0,506 & 0,667 \\
\hline POS4 & $\mathbf{0 , 8 0 6}$ & 0,446 & 0,695 \\
\hline POS5 & $\mathbf{0 , 8 2 0}$ & 0,564 & 0,708 \\
\hline MOW1 & 0,635 & $\mathbf{0 , 8 4 8}$ & 0,413 \\
\hline MOW2 & 0,665 & $\mathbf{0 , 8 7 7}$ & 0,478 \\
\hline MOW3 & 0,689 & $\mathbf{0 , 8 9 9}$ & 0,518 \\
\hline MOW4 & 0,786 & $\mathbf{0 , 8 1 5}$ & 0,584 \\
\hline MOW5 & 0,554 & $\mathbf{0 , 7 8 6}$ & 0,452 \\
\hline EC1 & 0,544 & 0,644 & $\mathbf{0 , 7 9 5}$ \\
\hline EC2 & 0,674 & 0,649 & $\mathbf{0 , 7 6 3}$ \\
\hline EC3 & 0,679 & 0,641 & $\mathbf{0 , 8 4 7}$ \\
\hline EC4 & 0,569 & 0,685 & $\mathbf{0 , 7 9 9}$ \\
EC5 & 0,733 & 0,505 & $\mathbf{0 , 7 4 1}$ \\
\hline
\end{tabular}

Tabel 2. Fornell Lacker

\begin{tabular}{|c|c|c|c|}
\hline Variabel & $\begin{array}{c}\text { Employee } \\
\text { Creativity }\end{array}$ & $\begin{array}{c}\text { Meaning } \\
\text { of Work }\end{array}$ & $\begin{array}{c}\text { Organizational } \\
\text { Support }\end{array}$ \\
\hline $\begin{array}{c}\text { Organizational } \\
\text { Support }\end{array}$ & 0,802 & 0,586 & $\mathbf{0 , 8 4 3}$ \\
\hline $\begin{array}{c}\text { Meaning of } \\
\text { Work }\end{array}$ & 0,797 & $\mathbf{0 , 8 4 6}$ & \\
\hline $\begin{array}{c}\text { Employee } \\
\text { Creativity }\end{array}$ & $\mathbf{0 , 7 9 0}$ & & \\
\hline
\end{tabular}


Dari tabel 4.1 hasil analisis cross loading menyatakan bahwa nilai dari indikator terhadap variabel latennya lebih besar dari pada nilai indikator terhadap variabel laten yang lain, dan hasil nilai ini terbukti untuk semua variabel terhadap variabel latennya dan telah memenuhi kriteria validitas diskriminan. Pada tabel 4.2 nilai AVE untuk setiap variabel konstruk lebih besar dari nilai korelasi antar konstruk, maka dapat dikatakan bahwa indikator setiap variabel telah memenuhi kriteria fornell-larcker atau dapat disimpulkan telah memenuhi validitas diskriminan.

Tabel 3. Hasil Average variance extracted

\begin{tabular}{|c|c|}
\hline Variabel & $\begin{array}{c}\text { Average variance } \\
\text { extracted }(A V E)\end{array}$ \\
\hline $\begin{array}{c}\text { Organizational } \\
\text { Support }\end{array}$ & 0,711 \\
\hline $\begin{array}{c}\text { Meaning of } \\
\text { Work }\end{array}$ & 0,716 \\
\hline $\begin{array}{c}\text { Employee } \\
\text { Creativity }\end{array}$ & 0,624 \\
\hline
\end{tabular}

Nilai dari Average Variance Extracted (AVE) setiap variabel menunjukan nilai di atas 0,5 yang artinya variabel tersebut sudah valid.

Tabel 4. Hasil Composite Realibility dan Cronbach's Alpha

\begin{tabular}{|l|l|l|}
\hline variabel & $\begin{array}{l}\text { Compostie } \\
\text { Reliability }\end{array}$ & $\begin{array}{l}\text { Cronbach's } \\
\text { Alpha }\end{array}$ \\
\hline $\begin{array}{l}\text { Organizational } \\
\text { Support }\end{array}$ & 0,924 & 0,898 \\
\hline Meaning of Work & 0,926 & 0,900 \\
\hline Employee Creativity & 0,892 & 0,849 \\
\hline
\end{tabular}

Kita dapat lihat bahwa tampilan nilai reliabilitas dengan uji composite reliability pada masing-masing variabel menunjukan nilai lebih dari 0,7 atau (Composite reliability > 0,7). dan uji reliabilitas dengan Cronbach's alpha dari masing-masing variabel memiliki nilai lebih dari 0,6 atau Cronbach's alpha > 6. Hal ini menujukan bahwa uji tersebut pada masingmasing variabel dinyatakan sebagai variabel yang reliabel.

Uji inner model. Uji model terdiri dari Koefisien determinasi, Predictive Relevance, path coefficient, Uji Effect Size

Tabel 5. Hasil Coefficient of Determination

\begin{tabular}{|l|l|}
\hline Variabel & $\mathbf{R}^{\mathbf{2}}$ \\
\hline Meaning of Work & 0,343 \\
\hline Employee & 0,636 \\
\hline
\end{tabular}




\section{Creativity}

Pada tabel 4.10 terdapat nilai koefisien determinasi yang menunjukan bahwa nilai 0,340 atau 34\% pada Meaning of Work dapat dijelaskan kontribusinya oleh Organizational Support, sedangkan Employee Creativity memiliki nilai sebesar 0,636 atau 63,6\% yang dapat dijelaskan kontribusinya oleh variabel Organizational Support dan Meaning of Work. Sisa pada nilai masing-masing variabel yaitu senilai $76 \%$ pada Meaning of Work dan 36,4\% pada Employee Creativity dapat dijelaskan kontribusinya oleh variabel lain diluar variabel dalam penelitian atau dapat dikatakan tidak dapat didefinisikan. Maka kesimpulan dalam penelitian ini menunjukan bahwa nilai $\mathrm{R}^{2}$ pada variabel Meaning of Work dan Organizational Support dikategorikan Substansial (kuat).

Tabel 6. Hasil Predictive Relevance

\begin{tabular}{|l|l|}
\hline variabel & $\mathbf{Q}^{2}$ \\
\hline Meaning of Work & 0,222 \\
\hline Employee Creativity & 0,364 \\
\hline
\end{tabular}

Dalam hasil uji predictive relevance pada tabel 4.11 menunjukan bahwa variabel independen pada Organizational Support dapat memprediksi variabel dependen dengan baik begitupun dengan variael dependen pada Employee Creativity dapat diprediksi dengan variabel dependen Meaning of Work, dan Organizational Support. Hasil tersebut didasari teori yang mengatakan bahwa apabila nilai $Q^{2}$ lebih besar dari pada nol (Hair, 2012). Pada hasil penelitian membuktikan bahwa predictive relevance pada Meaning of Work sebesar $0,222\left(\mathrm{Q}^{2}>\mathbf{0}\right)$ dan dan pada Employee Creativity sebesar 0,364 $\left(\mathrm{Q}^{2}>\mathbf{0}\right)$.

Tabel 7. Hasil Bootstraping

\begin{tabular}{|l|l|l|l|}
\hline \multirow{2}{*}{ Variabel } & \multicolumn{2}{|l|}{ Employee Creativity } \\
\cline { 2 - 4 } & $\begin{array}{l}\text { Path } \\
\text { coefficients }\end{array}$ & t-statistics & p-values \\
\hline Meaning of Work & 0,797 & 19,232 & 0 \\
\hline
\end{tabular}

Tabel 8. Hasil Bootsraping

\begin{tabular}{|l|l|l|l|}
\hline \multirow{2}{*}{ Variabel } & \multicolumn{3}{|l|}{ Meaning of Work } \\
\cline { 2 - 4 } & $\begin{array}{l}\text { Path } \\
\text { coefficients }\end{array}$ & t-statistics & p-values \\
\hline $\begin{array}{l}\text { Organizational } \\
\text { Support }\end{array}$ & 0,586 & 8,171 & 0 \\
\hline
\end{tabular}

Hasil dari nilai path coefficients (koefisien jalur), t-statistics dan juga p-value untuk masing-masing variabel independen terhadap variabel dependen didapatkan dari metode 
bootstrapping. Hasil yang didapatkan menyimpulkan bahwa seluruh variabel independen merupakan prediktor positif terhadap variabel dependen. Organizational Support merupakan prediktor positif terhadap Meaning of Work dengan nilai 0,586 Begitu pula dengan variabel Meaning of Work terhadap Employee Creativity sebagai prediktor yang positif dengan nilai 0,797 .

Tabel 9. Hasil Effect Size

\begin{tabular}{|l|l|l|}
\hline Variabel & Employee Creativity & $\begin{array}{c}\text { Meaning of } \\
\text { Work }\end{array}$ \\
\hline $\begin{array}{l}\text { Organizational } \\
\text { Support }\end{array}$ & - & 0,522 \\
\hline Meaning of Work & 1,746 & - \\
\hline
\end{tabular}

Nilai effect sizes pada penelitian ini yang terdapat pada tabel 4.14 dapat disimpulkan bahwa pada variabel Organizational Support memiliki efek besar terhadap Meaning of Work dengan nilai 0,522. Variabel Meaning of Work memiliki efek besar atau efek mempengaruhi terhadap perubahan Employee Creativity dengan nilai 1,746

Tabel 10. Hasil Bootsraping Indirect Effect

\begin{tabular}{|l|l|l|l|}
\hline \multirow{2}{*}{ variabel } & \multicolumn{3}{|c|}{ Employee Creativity } \\
\cline { 2 - 4 } & Path Coefficients & t-statistics & p-values \\
\hline $\begin{array}{l}\text { Organizational } \\
\text { Support }\end{array}$ & 0,467 & 6,026 & 0,000 \\
\hline
\end{tabular}

Dari hasil pada tabel diatas dapat disimpulkan bahwa peran variabel independen yang dapat memprediksi variabel dependen dengan adanya peran mediasi secara menyeluruh merupakan prediktor yang positif. Melalui uji indirect effect, variabel Organizational Support merupakan prediktor yang positif dengan nilai 0,467 terhadap variabel Employee Creativity melalui peran mediasi Meaning of Work.

\section{Hasil Pengujian Hipotesis}

\section{Hipotesis 1}

Ho 1: Terdapat pengaruh Organizational Support terhadap Meaning of Work

Hipotesis ini ingin membuktikan terkait dengan adanya pengaruh variabel Organizational Support terhadap Meaning of Work. Nilai t-statistics untuk hipotesis ini sebesar 8.171 (t-statistics > 1,96) dan nilai $\mathrm{p}$-value sebesar $0,000(\mathrm{p}<0,05)$. Maka dapat dikatakan dalam hipotesis ini dapat diterimah (tidak ditolak).

\section{Hipotesis 2}

\section{Ho 2: Terdapat pengaruh Meaning of Work terhadap Employee Creativity}

Hipotesis ini ingin membuktikan adanya hubungan pengaruh antara variabel Meaning of Work terhadap Employe Creativity. Nilai t-statistics untuk hipotesis ini sebesar 19,232 (tstatistics > 1,96) dan nilai dari $\mathrm{p}$ - value sebesar $0,000(\mathrm{p}<0,05)$. Maka dapat dikatakan bahwa hipotesis ini dapat diterima (tidak ditolak). 


\section{Hipotesis 3}

\section{Ho 3: Terdapat pengaruh Organizational Support terhadap Employee Creativity dengen} mediasi Meaning of Work

Hipotesis terakhir yang dibentuk ini menyatakan bahwa pengaruh Organizational Support terhadap Employee Creativity dengan pengaruh peran mediasi Meaning of Work. Melalui uji indirect effects maka menghasilkan nilai t-statistics sebesar 6,026 (t-statistics > 1,96) dan nilai dari $\mathrm{p}$-value sebesar $0,000(\mathrm{p}<0,05)$, sehingga hipotesis ini dapat dikatakan dapat diterima (tidak ditolak).

\section{KESIMPULAN}

Berdasarkan hasil penelitian makan dan penjelasan analisis yang telah di uraikan pada bab sebelumnya makan dapat ditarik kesimpulan bahwa hipotesis pertama (H1) terdapat pengaruh positif dukungan organisasi (organizational support) terhadap makna kerja (meaning of work) diterima. Artinya menunjukan bahwa karyawan dapat semakin memahami dan mengerti makna kerja yang dilakukan mereka apabila karyawan dapat merasakan dukungan secara nyatara dari atasan. Hipotesis ini didukung oleh penelitian yang sudah ada sebelumnya Wang, Z., \& Xu, H. (2019), Yilmaz Akgunduz (2017), dan Regina Martha Tanudjaja, (2013). Lalu hipotesis kedua (H2) menunjukan bahwa terdapat pengaruh positif antara makna kerja (meaning of work) dengan kreativitas karyawan (employee creativity) yang berarti karyawan yang sudah memahami dengan baik makna kerja yang mereka lakukan, mereka dapat menunjukan peningkatan kreativitas dan juga dapat menciptakan ideide baru untuk menyelesaikan permasalahan yang di hadapi perusahaan. Hipotesis ini juga didukung oleh penelitian yang sudah ada sebelumnya seperti Yilmaz Akgunduz, Ceylan Alkan, Oezge Adan Goek (2017), Yilmaz Akgunduz, Gaye Kizilcalioglu, Sabahat Ceylin Sanli (2016), dan Cohen-Meitar, R., Carmeli, A., \& Waldman, D. A. (2009). Kemudian Hipotesis ke 3 (H3) juga menunjukan terdapat pengaruh positif antara dukungan organisasi (organizational support) terhadap kreativitas karyawan (employee creativity) dengan mediasi makna kerja (meaning of work) yang memiliki arti kreativitas karyawan akan mengalami peningkatan secara maksimal apabila mereka dapat memahami makna kerja yang baik melalui dukungan organisasi, dukungan organisasi berperan untuk menjelaskan kepada karyawan apa itu makna kerja yang berujung pada peningkatan kreativitas karyawan. Hasil penelitian ini didukung oleh penelitian yang sudah ada sebelumnya Yilmaz Akgunduz, Ceylan Alkan, Oezge Adan Goek (2017).

\section{SARAN}

Berdasarkan hasil penealitian maka dapat disimpulkan bahwa Perceived Organizational Support memiliki pengaruh positif terhadap Employee Creativity dengan Meaning of Work sebagai Mediasi. Berdasarkan penelitian yang telah dilakukan, peneliti akan memberikan berapa saran yang diharapkan dapat berguna bagi perusahaan dan bermanfaat pula bagi penelitian sejenis yang akan dilakukan di masa mendatang. Disarankan agar perusahaan tetap mempertahankan variabel Organizational Support dengan indikator : masukan yang diberikan dari atasan. Dengan begitu karyawan dapat semakin mengerti makna kerja mereka. Perusahaan juga sebaiknya mengeksplorasi lebih dalam mengenai Emplpoyee Creativity, perusahaan sebaiknya memberikan perhatian lebih terhadap kondisi karyawan agar mereka dapat berpikir kreatif. Perusahaan juga sebaiknya meninjau kembali tentang hubungan variabel Organizational Support terhadap Meaning of Work, dengan begitu Employee Creativity pada karyawan dapat semakin meningkat. Bagi peneliti, sebaiknya memperluas 
variabel penentu dalam terbentuknya pengaruh Employee Creativity yang mengacu kepada penelitian sebelumnya dengan tujuan memperkaya hasil penelitian bagi ilmu pengetahuan. kemudian Bagi peneliti, sebaiknya memperluas jangkauan pengambilan sampel dengan tujuan dapat meningkatkan ketepatan dan keakuratan guna memperkuat hasil hipotesis dalam penelitianyang telah ada sebelumnya dan serta dapat dikatakan layak dalam merepresentasikan subjek yang luas.

\section{DAFTAR PUSTAKA}

Akgunduz, Y., Alkan, C., \& Gök, Ö. A. (2018). Perceived organizational support, employee creativity and proactive personality: The mediating effect of meaning of work. Journal of Hospitality and Tourism Management, 34, 105-114.

Akgunduz, Y., Kizilcalioglu, G., \& Sanli, S. C. (2018). The effects of job satisfaction and meaning of work on employee creativity: An investigation of EXPO 2016 exhibition employees. Turizam: međunarodni znanstveno-stručni časopis, 66(2), 130-147.

Blau, P. M. (1964). Social exchange theory. Retrieved September, 3(2007), 62.

Cohen-Meitar, R., Carmeli, A., \& Waldman, D. A. (2009). Linking meaningfulness in the workplace to employee creativity: The intervening role of organizational identification and positive psychological experiences. Creativity Research Journal, 21(4), 361-375.

Eisenberger, R., Huntington, R., Hutchison, S., \& Sowa, D. (1986). Perceived organizational support. Journal of Applied psychology, 71(3), 500.

Erdogan, B., \& Enders, J. (2007). Support from the top: Supervisors' perceived organizational support as a moderator of leader-member exchange to satisfaction and performance relationships. Journal of applied psychology, 92(2), 321.

Gaggiotti, H. (2006). Going from Spain and Latin America to Central Asia: decisionmaking of expatriation and meaning of work. The Central Asia Business Journal, 1(1), 8-22.

Gong, Y., Huang, J. C., \& Farh, J. L. (2009). Employee learning orientation, transformational leadership, and employee creativity: The mediating role of employee creative self-efficacy. Academy of management Journal, 52(4), 765-778.

Harpaz, I., \& Fu, X. (2002). The structure of the meaning of work: A relative stability amidst change. Human relations, 55(6), 639-667.

Joo, B. K., Yang, B., \& McLean, G. N. (2014). Employee creativity: The effects of perceived learning culture, leader-member exchange quality, job autonomy, and proactivity. Human Resource Development International, 17(3), 297-317.

Mondy, R. W., \& Martocchio, J. J. (2016). Human Resource Management (Fourteenth). England: Pearson Education Limited.

Scott, S.G. \& Bruce, R.A. (1994). Determinants of innovative behavior: A path model of individual innovation in the workplace. Academy of Management Journal, 37(3), 580-607.

Shalley, C. E., Zhou, J., \& Oldham, G. R. (2004). The effects of personal and contextual characteristics on creativity: Where should we go from here?.Journal of management, 30(6), 933-958.

Shin, S. J., Kim, T. Y., Lee, J. Y., \& Bian, L. (2012). Cognitive team diversity and individual team member creativity: A cross-level interaction. Academyof Management Journal, 55(1), 197-212.

Wang, Z., \& Xu, H. (2019). When and for whom ethical leadership is more effective in eliciting work meaningfulness and positive attitudes: The moderating roles of core self-evaluation and perceived 
Yu, C., \& Frenkel, S. J. (2013). Explaining task performance and creativity from perceived organizational support theory: Which mechanisms are more important?. Journal of Organizational Behavior, 34(8), 1165-1181.

Zhang, L., Bu, Q., \& Wee, S. (2016). Effect of perceived organizational support on employee creativity: Moderating role of job stressors. International Journal of Stress Management, 23(4), 400. 